\title{
AVALIAÇÃO DE LEIRAS ESTÁTICAS AERADAS NA COMPOSTAGEM DE CARCAÇAS DE FRANGO
}

Ed Carlo Rosa Paiva ${ }^{1}$, Antonio Teixeira de Matos $^{2}$, Renata Tâmara Pereira de Barros ${ }^{3}$, Tatiana Dias Ribeiro da $\mathrm{Costa}^{4}$, Antover Panazzolo Sarmento

\section{RESUMO}

O presente trabalho teve como objetivo avaliar a eficiência do processo de compostagem em leiras estáticas aeradas, com aeração positiva, no tratamento da carcaça de frango, utilizando como materiais estruturantes e fontes de carbono, bagaço de cana-de-açúcar; palha de café e cama-de-frango. Os indicadores de eficiência utilizados foram, na estabilização da matéria orgânica (redução de SV, relação C/N e o índice CTC/COT) e na higienização (redução de microrganismos, coliformes termotolerantes e Samonella). Foram avaliados e comparados diferentes tratamentos quanto à eficiência na higienização do composto e estabilização da matéria orgânica, utilizando-se leiras estáticas aeradas. Foram utilizados os seguintes tratamentos: LEA01: bagaço de cana de açúcar, cama de frango e carcaça de frango inteira; LEA02: bagaço de cana de açúcar, cama de frango e carcaça de frango triturada; LEA03: palha de café, cama de frango e carcaça de frango triturada. As variáveis monitoradas foram: temperatura, relação $\mathrm{C} / \mathrm{N}$, sólidos voláteis $(\mathrm{SV}), \mathrm{pH}, \mathrm{CTC}$ e conteúdo de água. Verificouse também a evolução do índice CTC/COT, eliminação de Salmonella e redução de coliformes termotolerantes. Ao final do experimento verificou-se que a palha de café proporcionou melhores resultados na compostagem da carcaça de frango que o bagaço de cana de açúcar, já que proporcionou maior redução nos valores de SV. Além disso, os materiais produzidos, já na primeira fase (fase ativa) da compostagem, apresentaram índices CTC/COT superiores aos considerados adequados $(1,7)$ para um composto considerado maturado. Quanto à higienização, a redução dos microrganismos Salmonella e coliformes termotolerantes atingiram níveis compatíveis com os estabelecidos na legislação CONAMA 375/2006.

Palavras-chave: higienização; leiras estáticas aeradas, degradação bioquímica.

\section{ABSTRACT}

\section{ASSESSMENT OF AERATED STATIC PILES IN THE COMPOSTING OF POULTRY CARCASSES}

This study aimed to evaluate the efficiency of the composting process in aerated static piles with positive aeration for the treatment of poultry carcasses, using cane sugar bagasse, coffee straw and poultry litter as bulking materials and carbon sources. Efficiency indicators used were based on stabilization of organic matter (reduced VS, the C/N ratio and CEC/ TOC) and sanitization (reduction of microorganisms, coliforms and Salmonella). Different treatments were evaluated and compared with regards to efficiency of sanitization of compost and organic matter stabilization, using aerated static piles. The following treatments (T) were utilized: T1 - sugar cane bagasse, poultry litter and poultry carcasses; T2 - sugar cane bagasse, poultry litter and ground poultry carcasses; T3 - coffee straw, poultry litter and ground poultry carcasses. The variables monitored were temperature, $\mathrm{C} / \mathrm{N}$ ratio, volatile solids (VS), $\mathrm{pH}, \mathrm{CEC}$ and water content. The data also showed the evolution of the CEC/TOC index $\geq 1.7$, the elimination of Salmonella and fecal coliform reduction. At the end of the experiment it was found that the coffee straw provided better results in composting of poultry carcass that sugar cane bagasse, since it resulted in greater reduction in the values of VS. Moreover, the material produced in the first composting phase (active phase), showed CEC/TOC index values higher than those considered suitable (1.7) for compost considered matured. As for sanitization, the Salmonella and fecal coliform microorganisms' reduction reached levels were consistent with those defined in the legislation CONAMA 375/2006.

Keywords: Sanitization, aerated static piles, biochemical degradation.

\section{Recebido para publicação em 20/09/2012. Aprovado em 07/06/2013.}

1 - Engenheiro Civil, D.S. em Eng. Agrícola. Professor Adjunto DECIV/CAC-UFG mail: edcarlopaiva@yahoo.com.br.

2 - Engenheiro Agrícola, D.S. em Solos e Nutrição de Plantas; Professor Associado DEA/UFV. E-mail: atmatos@ufv.br.

3 - Eng. Agrícola e Ambiental. Mestranda em Ciência e Tecnologia das Sustentabilidade da UNIFESP. natufv2004@yahoo.com.br

4 - Estudante de Engenharia Agrícola e Ambiental da UFV. tatianadias749@hotmail.com.

5 - Engenheiro Agrícola, M.S. em Engenharia Agricola; Professor Assistente DECIV/CAC-UFG. E-mail: antoverps@gmail.br.

482 REVENG 482-492p.

ENGENHARIA NA AGRICULTURA, VIÇOSA - MG, V.21 N.5, SETEMBRO / OUTUBRO 2013 


\section{INTRODUÇÃO}

O elevado crescimento populacional no planeta tem gerado, proporcionalmente, uma maior demanda por alimentos, e, consequentemente, grande quantidade de resíduos, o que constitui grande problema de ordem social, econômica e ambiental. Dentre as atividades produtoras de alimentos encontra-se a produção de frangos de corte.

O Brasil é o terceiro maior produtor mundial de carne de frango, ficando atrás apenas dos Estados Unidos e da China, sendo o maior exportador de carne de frango do mundo. Segundo dados da UBA (União Brasileira de Avicultura), em 2009, o Brasil produziu aproximadamente 11 milhões de toneladas, o que representou no cenário mundial cerca de $15 \%$, ficando atrás dos Estados Unidos com, aproximadamente, 16 milhões de toneladas $(22 \%)$ e a China cerca 12 milhões de toneladas $(16,9 \%)$. O mesmo relatório relata que a carne de frango se encontra em segundo lugar no ranking da produção mundial de carnes, com 71,7 milhões de toneladas. $\mathrm{O}$ valor apresentado, correspondente a um aumento de $0,39 \%$ em relação ao ano de 2008, embora aparentemente pequeno é, na visão de especialistas, reflexo positivo, considerando-se tratar de um período de recuperação econômica mundial após a crise iniciada em 2008.

Com o aumento na produção de carne de frango, agrega-se um proporcional aumento na quantidade de resíduos gerados na atividade de criação dessas aves. Considerando que cada ave de corte produz de 1 a $1,5 \mathrm{~kg}$ de excretas durante a criação (LUCAS JUNIOR; AMORIM, 2005), e que o Brasil produziu aproximadamente 5,13 bilhões de frangos em 2011 (SILVA, 2012), que significou uma produção de, aproximadamente, 6,4 milhões de toneladas de excretas, naquele ano, no Brasil.

Segundo a Associação de Avicultores da Zona da Mata de Minas Gerais (AVIZOM) a cama de frango descartada dos criatórios, antes Instrução Normativa $\mathrm{n}^{\circ} 8$, do Ministério da Agricultura, Pecuária e Abastecimento (MAPA, 2004), que proibiu a prática de alimentar outros animais com a cama de frango, não constituía problema ambiental. Ao contrário, essa cama de frango era responsável pela viabilidade econômica do sistema de integração de frango na região, uma vez que todo esse material era comercializado como suplemento alimentar de gado. Entretanto, segundo a mesma entidade, as carcaças de aves mortas durante a fase de criação eram enterradas, lançadas nos rios da região, ou ainda, utilizadas como alimento para outros animais.

Nesse sentido, torna-se urgente o desenvolvimento de tecnologias que possibilite a destinação adequada, sob o ponto de vista sanitário e ambiental, se possível, com o aproveitamento desse resíduo para fins agrícolas.

Um das técnicas mais difundidas em todo mundo para o tratamento e disposição de resíduos orgânicos é a compostagem. Essa técnica apresenta uma série de variantes, tais como leiras reviradas manualmente ou mecanicamente, leiras estáticas, reatores fechados mecanizados e composteiras, utilizadas no tratamento dos mais diferentes tipos de resíduos orgânicos.

A técnica da compostagem, sendo bem conduzida, produz como produto final um material estabilizado quimicamente e livre de microrganismos patogênicos. Tal produto, denominado composto, caracteriza-se por ser um material humificado e excelente condicionador do solo.

Estudos sobre compostagem em leiras tem sido desenvolvidos para diferentes tipos de resíduos, como bagaço de cana-de-açúcar, capim Napier picado, palha de café, aparas de madeira e resíduo de suinocultura (MATOS et al., 1998; ROS et al., 2006; CHIUMENTI et al., 2007), utilizando reviramento; lodos de águas residuárias e a fração orgânica dos resíduos sólidos urbanos (PEREIRA NETO et al., 1991; STENTIFORD et al., 1996; SESAY et al., 1998; GUARDIA et al., 2008, RASAPOOR et al., 2009; WANG et al., 2011); utilizando leiras estáticas aeradas.

A compostagem de carcaças de aves, entretanto, tem sido desenvolvida, basicamente, pelo método da composteira, em geral, seguido do processo de leiras por reviramento manual (COSTA et al., 2006; KUMAR et al., 2007; ORRICO JUNIOR et al., 2010; PAIVA et al., 2012). Segundo Graves et al. (2000), a compostagem de carcaças em composteira é a técnica de tratamento de custo e tecnologia mais acessível aos produtores de aves. 
Entretanto, o processo por Leiras Estáticas Aeradas (LEAs) tem sido um dos mais difundidos para o tratamento de resíduos orgânicos por apresentar custos de operação similares ao processo "Windrow", além de ser o único processo que combina adequada eliminação de patógenos com alto grau de estabilização do material orgánico (GOLUEKE, 1980; STENTIFORD et al., 1996). Devido a essas características, acredita-se que tal processo possa ser excelente alternativa à crescente demanda de tratamento e disposição final dos resíduos gerados na produção de carnes de frango no Brasil.

O presente trabalho objetivou avaliar a eficiência do processo de compostagem em leiras estáticas aeradas, com aeração positiva, no tratamento da carcaça de frango, utilizando como materiais estruturantes e fontes de carbono: i) bagaço de cana-de-açúcar; ii) palha de café e iii) cama-defrango. Os indicadores de eficiência utilizados foram, na estabilização da matéria orgânica (redução de $\mathrm{SV}$, relação $\mathrm{C} / \mathrm{N}$ e o índice $\mathrm{CTC} / \mathrm{COT}$ ) e na higienização (redução de micro-organismos, coliformes termotolerantes e Samonella).

\section{MATERIAL E MÉTODOS}

Os experimentos foram conduzidos em duas etapas, no período de julho de 2007 a janeiro de 2008. Os experimentos foram conduzidos em áreas experimentais do Departamento de Engenharia Agrícola (DEA) da Universidade Federal de Viçosa (UFV). As análises foram realizadas no Laboratório de Solo e Resíduos Sólidos do DEA e Laboratório de Microbiologia de Alimentos - Departamento de Microbiologia (análises bacteriológicas), ambos da UFV.

$\mathrm{Na}$ primeira etapa objetivou-se encontrar a proporção ótima dos resíduos a serem compostados mediante a determinação da relação carbono-nitrogênio $(\mathrm{C} / \mathrm{N})$ de cada material e da perda de pressão do ar ao passar pela massa em compostagem, sendo que, nesse caso, foi adotada a mesma metodologia utilizada por Moreira et al. (2008) e Silva et al. (2008).

$\mathrm{Na}$ segunda etapa, foram montadas e monitoradas LEAs com a seguinte composição e dimensões, respectivamente: LEA01: carcaças inteiras de frango, bagaço de cana-de-açúcar e cama de frango, seção transversal trapezoidal e medidas aproximadas de $2 \mathrm{~m}$ de base maior, 1, 5 $\mathrm{m}$ de base menor, 1 metro de altura e comprimento de $3 \mathrm{~m}$. LEA02: carcaças de frango trituradas, bagaço de cana-de-açúcar e cama de frango, seção triangular e medidas aproximadas de $2 \mathrm{~m}$ de base, 1 metro de altura e comprimento de $3 \mathrm{~m}$. LEA03: carcaças de frango trituradas, palha de café e cama de frango, seção triangular e medidas aproximadas de $2 \mathrm{~m}$ de base, 1 metro de altura e comprimento de $3 \mathrm{~m}$. A LEA01 foi montada em camadas segundo recomendações de Dam et al. (2009) e as LEA02 e LEA03, segundo recomendações de Pereira Neto (1987). Cada uma das LEAs possuía um ventilador centrífugo (motor elétrico de $1 / 4 \mathrm{HP}$ de potência) de funcionamento controlado por timer analógico (precisão de 15 minutos) e termostato digital (precisão de $0,1^{\circ} \mathrm{C}$ ). A vazão de ar média utilizada foi de $4 \mathrm{~m}^{3} \mathrm{~min}^{-1}$.

As variáveis monitoradas foram: temperatura (diariamente), em três pontos da massa (base, centro e topo), relação Carbono/Nitrogênio e sólidos voláteis (SV) (a cada 15 dias) e os valores de Capacidade de Troca Catiônica (CTC), bem como os índices CTC/COT foram determinados, segundo Harada e Inoko (1980), somente para 60 e 90 dias. O teor de SV foi determinado pelo método da ignição, segundo Kiehl (1985), o carbono orgânico total (COT) foi obtido pela expressão (COT=SV/1.8). A relação $\mathrm{C} / \mathrm{N}$ foi determinada utilizando o carbono orgânico facilmente oxidável (CFO), sendo este determinado segundo o método de Walkley-Black (DEFELIPO, 1997) e o nitrogênio total segundo o método Kjedahl (APHA, 2005). As análises bacteriológicas foram realizadas segundo a IN 62 de 26 de agosto de 2003, Ministério da Agricultura Pecuária e Abastecimento.

Foram ajustadas equações de regressão, para as variáveis relação $\mathrm{C} / \mathrm{N}$ e $\mathrm{SV}$, para cada tratamento, obtidas com as medições ao longo do tempo de degradação das leiras. Os parâmetros obtidos pelas equações de regressão para cada tratamento foram considerados variáveis dependentes e submetidos à análise de agrupamento por otimização de Tocher, verificando a formação de grupos com base na distância euclidiana, para determinar quais tratamentos possuem comportamento similar. 
Após o agrupamento, obtiveram-se as equações de regressão para os grupos formados. Para isso utilizou-se o programa estatístico SAEG (RIBEIRO JÚNIOR, 2001).

\section{RESULTADOS E DISCUSSÃO}

Na Figura 1 estão apresentadas as variações de temperatura em função do tempo de compostagem nos tratamentos composteira (primeira e segunda fase), LEA 01, LEA 02 e LEA 03, respectivamente.

Conforme pode ser observado na Figura 1a a temperatura do material da LEA01 subiu gradativamente, no início do processo, atingindo 60 ${ }^{\circ} \mathrm{C}$ (centro) no sexto dia após a montagem da leira. Manteve-se próxima ou acima de $55^{\circ} \mathrm{C}$, em todos os pontos monitorados, por 8 dias, provavelmente enquanto as condições de umidade e aeração eram adequadas. Na LEA02 (Figura 1b), a temperatura

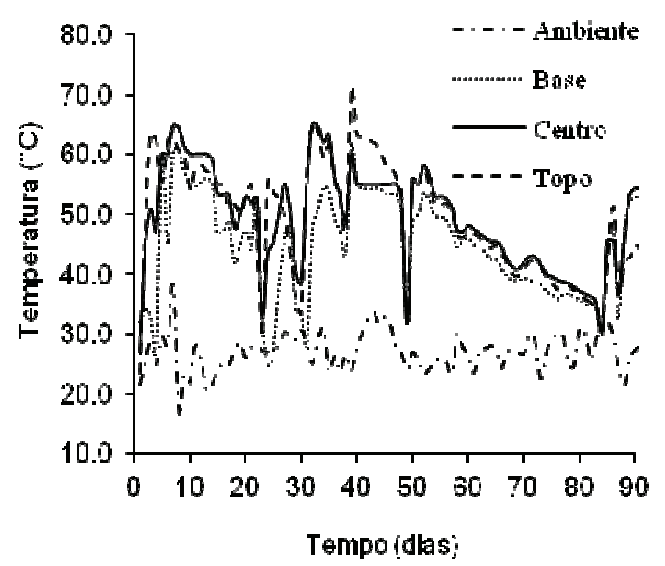

(a)

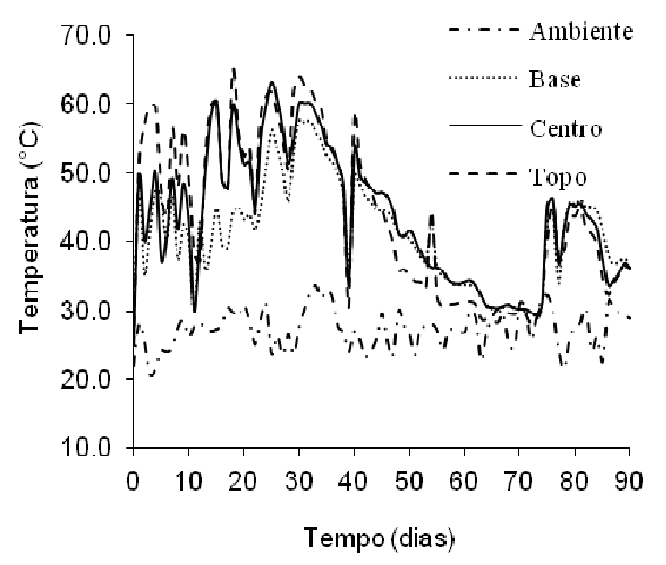

aumentou gradativamente atingindo $50{ }^{\circ} \mathrm{C}$ (centro) no $3^{\circ}$ dia após a montagem. Acredita-se que taxa de aeração inadequada, associada à falta de um sistema eficiente de umedecimento fez com que o material apresentasse, em grande parte do tempo, temperaturas próximas a $40{ }^{\circ} \mathrm{C}$, valor insuficiente para se conseguir controle sanitário do composto. Segundo Wang et al. (2011), o escoamento de ar unidirecional pode causar diferenças espaciais no conteúdo de água no material, o que poderia causar prejuízos à dinâmica da degradação microbiana $\mathrm{e}$ ao progresso da compostagem no sistema estático. $\mathrm{Na}$ LEA03 (Figura 1c), a temperatura aumentou gradativamente atingido $60^{\circ} \mathrm{C}$ (topo) já no $3^{\circ}$ dia após a montagem da leira. Stentiford et al. (1996) consideraram que temperaturas superiores a 55 ${ }^{\circ} \mathrm{C}$, por no mínimo três dias, são suficientes para sanitizar o composto, enquanto que a degradação máxima ocorre entre $45{ }^{\circ} \mathrm{C}$ e $55^{\circ} \mathrm{C}$ e a máxima

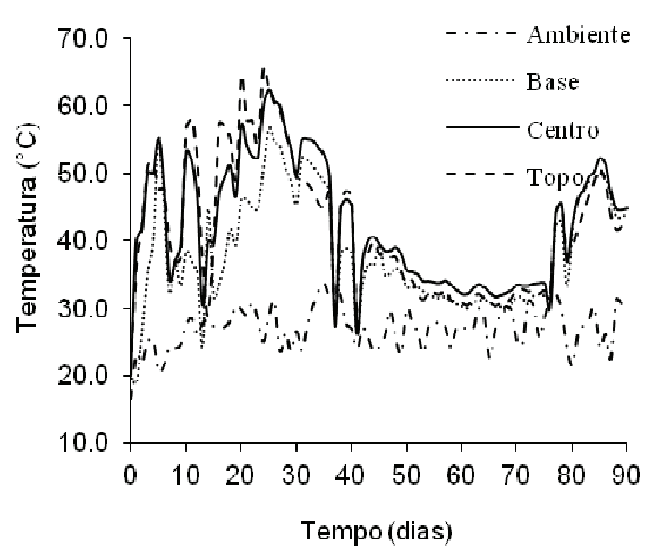

(b) (c) (a)

(b)

(c)

LEA 01

LEA 02

LEA 03

Figura 1. Variação da Temperatura em função do tempo de compostagem. 
diversidade microbiana ocorre quando as temperaturas estiverem entre $35^{\circ} \mathrm{C}$ e $40{ }^{\circ} \mathrm{C}$.

Em termos gerais, as LEAs 02 e 03 tiveram, nos primeiros 15 dias, comportamento muito semelhante, denotado por baixas temperaturas no material, ocorrendo alguns picos depois de efetuada a correção no conteúdo de água do material, como ocorreu a partir do $23^{\circ}$ dia de compostagem, quando foi instalado o sistema de umedecimento do material. Nessa ocasião, as temperaturas alcançaram valores dentro da faixa ideal para eliminação de patógenos, que está entre $55^{\circ} \mathrm{C}$ a $60{ }^{\circ} \mathrm{C}$, mantendo-se nessa faixa por um período de até 12 dias, enquanto que, antes da instalação do sistema de umedecimento, a temperatura se manteve acima de $50{ }^{\circ} \mathrm{C}$ por um período de três a cinco dias.

Observou-se, em todos os tratamentos, a elevação da temperatura sempre que o conteúdo de água do material era corrigido para, aproximadamente, 55 dag $\mathrm{kg}^{-1}$. Entretanto, a temperatura da base das leiras se manteve sempre inferior às demais. Isto se deve ao fato da sua proximidade com o duto de aeração, locais em que a perda de água foi mais rápida que a dos demais pontos da leira. Tal fato favoreceu um gradiente de temperatura no sentido ascendente, proporcionando a migração de umidade e sua condensação a cerca de $0,10 \mathrm{~m}$ da superfície das leiras.

Segundo Sesay et al. (1998), o gradiente de temperatura no material de leiras estáticas submetidos à aeração é função do fluxo de ar, do sentido de escoamento do ar e da reatividade da massa em compostagem. Como o ar ambiente, mais frio, é introduzido na massa de compostagem pela sua base, essa região sofre um resfriamento mais rápido que o topo, onde o calor é mais dificilmente dissipado.

No Quadro 1 estão apresentados os valores obtidos para variáveis como relação $\mathrm{C} / \mathrm{N}, \mathrm{SV}$ e CTC monitoradas durante a pesquisa, além dos valores calculados para o índice CTC/COT.

Como pode ser observado no Quadro 1, o valor da relação $\mathrm{C} / \mathrm{N}$ em todas as leiras se elevou durante

Quadro 1. Variação da relação C/N, SV e CTC e valores calculados para o índice CTC/COT

\begin{tabular}{|c|c|c|c|c|c|c|}
\hline Tratamentos & Dias & $\mathrm{C} / \mathrm{N}_{1}$ & SV (dag kg $\left.{ }^{-1}\right)$ & pH & CTC $\left(\mathrm{cmo}_{\mathrm{c}} \mathrm{kg}^{-1}\right)$ & CTC/COT \\
\hline \multirow{6}{*}{ LEA 01} & 0 & 13,8 & 86,0 & - & Não analisado & Não analisado \\
\hline & 15 & 5,8 & 82,9 & 6,3 & Não analisado & Não analisado \\
\hline & 30 & 8,9 & 74,7 & 8,6 & Não analisado & Não analisado \\
\hline & 45 & 9,3 & 71,4 & 9,3 & Não analisado & Não analisado \\
\hline & 60 & 17,9 & 61,8 & 8,6 & 180,0 & 5,3 \\
\hline & 90 & 18,1 & 60,7 & 9,2 & Análise perdida & Análise perdida \\
\hline \multirow{6}{*}{ LEA 02} & 0 & 13,8 & 86,0 & - & Não analisado & Não analisado \\
\hline & 15 & 9,0 & 75,5 & 7,5 & Não analisado & Não analisado \\
\hline & 30 & 8,9 & 67,9 & 9,2 & Não analisado & Não analisado \\
\hline & 45 & 8,4 & 67,3 & 9,0 & 196,0 & 5,2 \\
\hline & 60 & 15,1 & 55,6 & 8,6 & 215,0 & 7,0 \\
\hline & 90 & 14,6 & 61,2 & 9,3 & 197,0 & 5,8 \\
\hline \multirow{6}{*}{ LEA 03} & 0 & 13,6 & 86,1 & - & Não analisado & Não analisado \\
\hline & 15 & 8,4 & 80,9 & 7,0 & Não analisado & Não analisado \\
\hline & 30 & 7,5 & 72,9 & 9,0 & Não analisado & Não analisado \\
\hline & 45 & 8,0 & 61,5 & 9,3 & 183,0 & 4,5 \\
\hline & 60 & 17,8 & 63,2 & 9,1 & Análise perdida & Análise perdida \\
\hline & 90 & 17,4 & 39,2 & 8,9 & 212,0 & 9,7 \\
\hline
\end{tabular}

1 - A relação $\mathrm{C} / \mathrm{N}$ inicial foi calculada por balanço de massa e as demais por amostragem composta. 
o processo. Flynn e Wood (1996), analisando as mudanças químicas e de temperaturas na compostagem de cama de frango, observaram, em leiras que iniciaram com relação $\mathrm{C} / \mathrm{N}$ de $26,26 \mathrm{e}$ 24:1, após 84 dias de compostagem, que as relações $\mathrm{C} / \mathrm{N}$ foram aumentadas ou ligeiramente reduzidas para valores de 27,28 e $22: 1$, respectivamente. Kim et al. (2010), estudando a influência da taxa de aeração na dinâmica do nitrogênio na compostagem, observaram que altas taxas de aeração foram responsáveis por cerca de $85 \%$ da remoção de nitrogênio na forma de $\mathrm{NH}_{3}$. Tal como observado por esses autores, as LEAs apresentaram maior perda de nitrogênio que a Composteira; entretanto, a relação $\mathrm{C} / \mathrm{N}$ final nos primeiros ficou bem inferior à obtida no material processado na composteira. Acredita-se que isso se deva, também, à maior eficiência das LEAs na estabilização da matéria orgânica, denotada pela redução de SV. Kumar et al. (2007), trabalhando com composteira, também observaram aumento no valor da relação $\mathrm{C} / \mathrm{N}$ no composto final, em comparação com o obtido inicialmente. Esses autores obtiveram valores finais de relação $\mathrm{C} / \mathrm{N}$ de $15,9( \pm 0,76)$ a $23,19( \pm 4,62)$, no tratamento com palha de arroz, e de $16,35( \pm 1,06)$ a $18,0( \pm 1,64)$, no tratamento com feno de sorgo. Entretanto, Matos et al. (1998), cuja compostagem teve a relação $\mathrm{C} / \mathrm{N}$ inicial do material variando, aproximadamente, entre $30 \mathrm{e}$ 45:1, chegaram ao final do processo com a relação $\mathrm{C} / \mathrm{N}$ em torno de 15:1. O comportamento observado neste trabalho, bem como nos demais cuja relação $\mathrm{C} / \mathrm{N}$ inicial estava bem abaixo de 30:1, pode ser atribuída à perda de nitrogênio pela volatilização da amônia, sendo que essa perda foi potencializada pelos valores de $\mathrm{pH}$ básicos e altas temperaturas alcançadas durante o processo, bem como pela taxa de aeração a que material foi submetida. Sesay et al. (1998), trabalhando com sistemas híbridos (ora com aeração positiva, ora com aeração negativa), observaram que as temperaturas e $\mathrm{pH}$ alcançados no meio, favoreceu maior liberação de nitrôgenio na forma de amônia, se comparado ao sistema com aeração positiva. Kim et al. (2010), estudando a influência da taxa de aeração na dinâmica do nitrogênio na compostagem, observaram que altas taxas de aeração foram responsáveis por cerca de 85 \% da remoção de nitrogênio na forma de $\mathrm{NH}_{3}$.

Quanto aoíndice CTC/COT, os seguintes valores foram obtidos, aos 90 dias de compostagem: 5,3 (LEA011), 5,8 (LEA02) e 9,7 (LEA03). Segundo Harada e Inoko (1980), idealizadores do índice CTC/COT, um bom composto deve ter índice superior a 1,7 .

No Quadro 2 estão apresentadas as equações de regressão, referentes à relação $\mathrm{C} / \mathrm{N}$ estimadas para os três tratamentos, bem como os grupos formados pela análise de agrupamento por otimização de Tocher. Na Figura 2 encontram-se apresentadas as curvas, referentes às equações apresentadas no Quadro 2, que representam os modelos comuns obtidos após o agrupamento, utilizando-se o método de Tocher.

Conforme pode ser observado na Figura 2, este é um comportamento típico desse tipo de compostagem, no qual a relação $\mathrm{C} / \mathrm{N}$ inicial é muito baixa. Quando a relação $\mathrm{C} / \mathrm{N}$ se encontra entre 25 a 40:1, como em grande parte dos sistemas

Quadro 2. Grupos formados pela análise de agrupamento por otimização de Tocher para as curvas de tendência da relação $\mathrm{C} / \mathrm{N}$ ao longo do tempo e as equações de regressão estimadas para todos os tratamentos

\begin{tabular}{|c|c|c|c|}
\hline Grupos & Tratamentos & Regressão & $\mathbf{R 2}$ \\
\hline \multirow{2}{*}{1} & LEA02 & $\mathrm{C} / \mathrm{N}=-0,000101 \mathrm{t}^{3}+0,015578 \mathrm{t}^{2}-0,575135 \mathrm{t}+14,058282$ & 0,8597 \\
\hline & LEA03 & $\mathrm{C} / \mathrm{N}=-0,000140 \mathrm{t}^{3}+0,021364 \mathrm{t}^{2}-0,748958 \mathrm{t}+14,065114$ & 0,8744 \\
\hline \multicolumn{2}{|c|}{ Modelo Comum } & $C / N=-0,000121 t^{3}+0,018471 t^{2}-0,662046 t+14,061698$ & $\mathbf{0 , 8 2 2 8}$ \\
\hline 2 & LEA01 & $\mathrm{C} / \mathrm{N}=-0,000158 \mathrm{t}^{3}+0,023507 \mathrm{t}^{2}-0,788182 \mathrm{t}+13,679607$ & 0,9228 \\
\hline \multicolumn{2}{|c|}{ Modelo Comum } & $C / N=-\mathbf{0 , 0 0 0 1 5 8} t^{3}+0,023507 t^{2}-0,788182 t+13,679607$ & 0,9228 \\
\hline
\end{tabular}




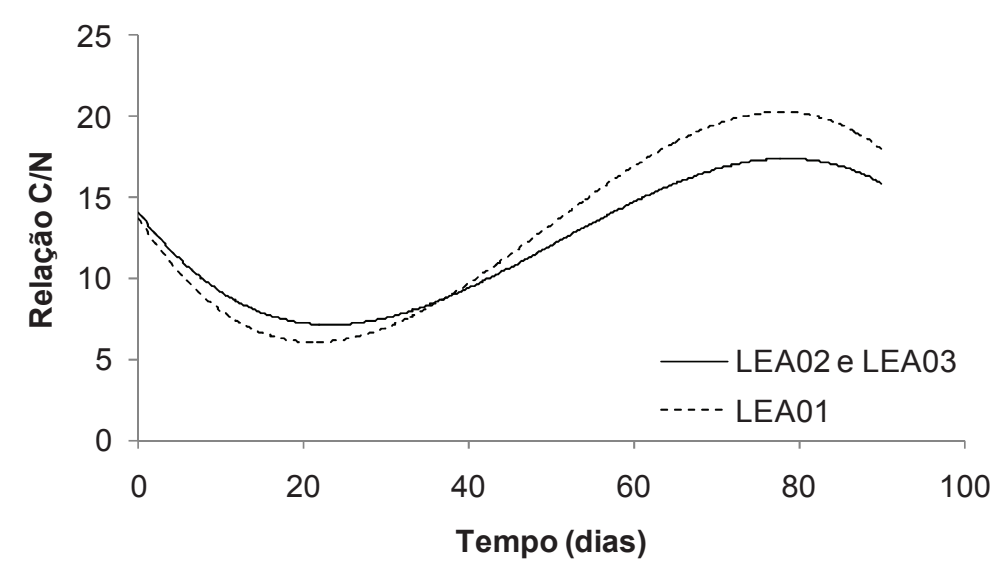

Figura 2. Curvas de tendência da relação $\mathrm{C} / \mathrm{N}$ ao longo do tempo, obtidas com as equações ajustadas para os diferentes tratamentos avaliados e agrupadas pelo método de Tocher (Quadro 2).

Quadro 3. Grupos formados pela análise de agrupamento por otimização de Tocher para análise de tendência da variável SV ao longo do tempo e as equações de regressão estimadas para todos os tratamentos

\begin{tabular}{|c|c|c|c|}
\hline Grupos & Tratamentos & Regressão & $\mathbf{R 2}$ \\
\hline \multirow{2}{*}{1} & LEA01 & $\mathrm{SV}=85,887803 \mathrm{e}^{-0,004311 \mathrm{t}}$ & 0,9270 \\
\hline & LEA02 & $\mathrm{SV}=80,286160 \mathrm{e}^{-0,004065 \mathrm{t}}$ & 0,7366 \\
\hline \multicolumn{2}{|c|}{ Modelo Comum } & $\mathrm{SV}=83,039760 \mathrm{e}^{-0,004188 \mathrm{t}}$ & 0,7904 \\
\hline 2 & LEA03 & $\mathrm{SV}=91,564844 \mathrm{e}^{-0,008431 \mathrm{t}}$ & 0,9251 \\
\hline \multicolumn{2}{|c|}{ Modelo Comum } & $\mathrm{SV}=91,564844 \mathrm{e}^{-0,008431 \mathrm{t}}$ & 0,9251 \\
\hline
\end{tabular}

de compostagem, o comportamento esperado é exponencial, tal como relatado por Matos et al. (1998). A relação $\mathrm{C} / \mathrm{N}$ inicial muito baixa indica altas concentrações de nitrogênio, acima daquelas exigidas pelos micro-organismos que degradam a matéria orgânica. Sendo assim, os microorganismos, presentes na massa de compostagem, ao degradarem a matéria orgânica favorecem a liberação do nitrogênio, que se encontra em excesso, elevando-se a relação $\mathrm{C} / \mathrm{N}$ para valores dentro da faixa mencionada acima, para depois então essa começar a declinar. Nesse sentido, observa-se que a trituração das carcaças favoreceu a volatilização da amônia a partir do $30^{\circ}$ dia de compostagem, período em que o $\mathrm{pH}$ se encontrava acima de 8,5 . Esse fato pode ter sido favorecido pela formação de "pelotas", pequenas bolas de carne envolvidas com cama de frango e, portanto, com baixa relação $\mathrm{C} / \mathrm{N}$, além de uma maior superfície específica para atividade microbiana.

No Quadro 3 estão apresentadas as equações de regressão, referentes à SV estimadas para os três tratamentos, bem como os grupos formados pela análise de agrupamento por otimização de Tocher. Na Figura 3 encontram-se apresentadas as curvas, referentes às equações apresentadas no Quadro 3, que representam os modelos comuns obtidos após o agrupamento, utilizando-se o método de Tocher.

Conforme pode ser observado na Figura 3, a partir do $30^{\circ}$ dia a LEA03 passou a apresentar valores de SV inferiores aos das LEA01 e LEA02. Tal fato certamente foi favorecido em função da palha de café ser um material de mais fácil degradação que o bagaço de cana de açúcar. A redução de SV das LEA 01, LEA 02 e LEA 03, após 90 dias, foram cerca de $25 \%, 29 \%$ e 54,5\%, respectivamente. Wang et al. (2011), trabalhando com compostagem de material orgânico com 


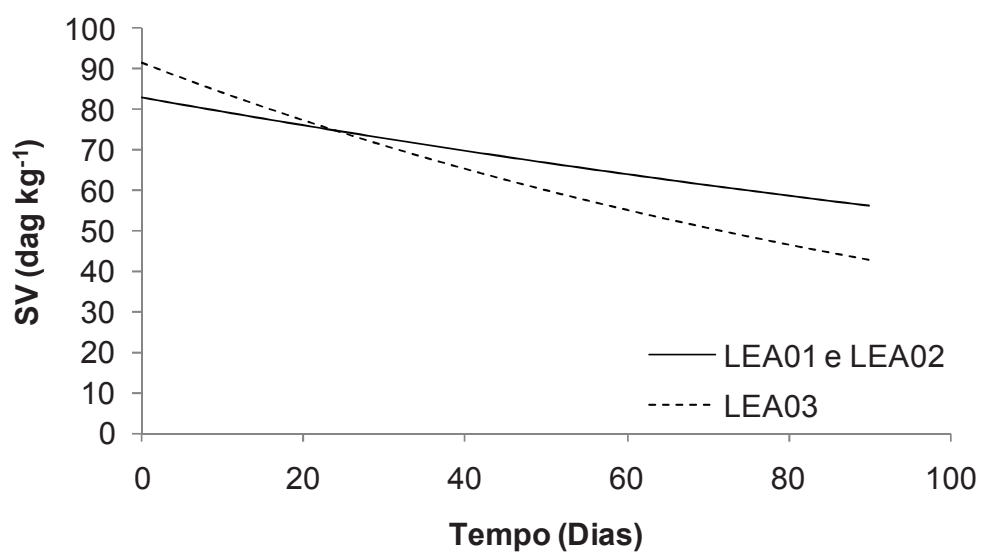

Figura 3. Curvas de tendência da variável SV ao longo do tempo, obtidas com as equações ajustadas para os diferentes tratamentos avaliados e agrupadas utilizando-se o método de Tocher (Quadro 3).

Quadro 4. Variáveis microbiológicas avaliadas durante a pesquisa:

\begin{tabular}{ccccc}
\hline Microrganismos & Dias & LEA 01 & LEA 02 & LEA 03 \\
\hline & 0 & $4,6 \times 10^{6}$ & $2,4 \times 10^{6}$ & $1,5 \times 10^{6}$ \\
Coliformes a 45 ${ }^{\circ} \mathrm{C}$ & 15 & $<3$ & 9,2 & 3,6 \\
$\left(\right.$ NMP g $\left.^{-1}\right)$ & 30 & 3,6 & $<3$ & $<3$ \\
& 60 & Não analisado & Não analisado & Não analisado \\
\hline & 0 & Ausência & Presença & Ausência \\
Salmonella & 15 & Ausência & Ausência & Ausência \\
$(25$ g) & 30 & Ausência & Ausência & Ausência \\
& 60 & Não analisado & Não analisado & Não analisado \\
\hline
\end{tabular}

aeração positiva, encontraram cerca de $17 \%$ de redução na concentração de $\mathrm{SV}$ em 18 dias de processamento. Azevedo (1993), na compostagem da fração orgânica de resíduos sólidos urbanos (RSU) pelo método de leiras estáticas aeradas, com aeração positiva e com aeração negativa, encontrou, respectivamente em média, reduções na concentração de SV de, aproximadamente, 33\% depois de 30 dias de aeração e $12 \%$ depois de 57 dias de aeração.

No Quadro 4 estão apresentados os resultados das análises microbiológicas de Salmonella e coliformes termotolerantes, efetuadas durante o período de compostagem.

De acordo com os resultados apresentados no Quadro 2 e com base no CONAMA 375/2006, que exige a ausência de Salmonella em amostra de $10 \mathrm{~g}$ de ST e contagem de organismos coliformes termotolerantes menor que $10^{3} \mathrm{NMP}^{-1}$ de ST, pode ser observado que todos os tratamentos proporcionaram resultados satisfatórios, já nas primeiras análises (15 dias). Entretanto, análises sucessivas deveriam ser feitas para confirmação dos resultados. Este cuidado é muito importante, pois devido à heterogeneidade da massa de compostagem pode ocorrer uma recontaminação do material. Sesay et al. (1998), após o reviramento do material para correção do conteúdo de água, ocorrido depois de 20 dias do inicio do processo de compostagem com aeração forçada, consideraram a recontaminação da massa de compostagem por microrganismos presentes nas camadas mais 
externas, uma vez que as temperaturas naquela região não alcançaram valores suficientes para promover a sanitização. Tal fato corrobora a necessidade de, mesmo em processo de leira estática aerada, haver o reviramento, pelo menos uma vez ao longo do período de compostagem, tomando-se o cuidado de colocar as camadas externas de material no interior das leiras.

Costa et al. (2006), trabalhando com carcaças submetida ao processo de composteira, porém adicionando $1 \mathrm{~L}$ de substrato contendo Salmonella $s p$ na diluição de $10^{8}$ unidades por $\mathrm{mL}$, na última camada da pilha em compostagem, com área aproximada de quatro metros quadrados, não conseguiram a eliminação satisfatória desses microrganismos na primeira fase do processo. Sendo, então, sugerida pelos autores, a necessidade de uma segunda fase de compostagem.

\section{CONCLUSÃO}

- A palha de café proporcionou melhores resultados na compostagem da carcaça de frango que o bagaço de cana de açúcar, já que proporcionou maior redução nos valores de $\mathrm{SV}$;

- Os materiais produzidos, já na primeira fase (fase ativa) da compostagem, apresentaram coeficientes de humificação muitas vezes superiores aos considerados adequados $(1,7)$ para um composto considerado maturado;

- Quanto à higienização, a redução dos microrganismos Salmonella e coliformes termotolerantes atingiram níveis compatíveis com os estabelecidos na legislação CONAMA $375 / 2006$, criada para lodo de esgoto doméstico.

\section{REFERÊNCIAS BIBLIOGRÁFICAS}

AMERICAN PUBLIC HEALTH ASSOCIATION - Standard methods for the examination of water and wastewater. New York: APHA, WWA. WPCR, 21 ${ }^{\text {th }}$ Ed., 2005

AVIZOM - Associação dos Avicultores da Zona da Mata. Projeto de pesquisa: Cama de frango.
Visconde do Rio Branco - MG, fevereiro de 2006. Texto não publicado.

AZEVEDO, M. A. Estudo e avaliação de quatro modos de aeração para sistemas de compostagem em leiras. 1993. 230f. (Dissertação de Mestrado em Engenharia Sanitária e Ambiental) Escola de Engenharia da UFMG, - Universidade Federal de Minas Gerais, Belo Horizonte, 1993.

BRASIL， MINISTÉRIO DA AGRICULTURA PECUÁRIA E ABASTECIMENTO. Instrução Normativa No. 8/2004. Proíbe em todo território nacional a produção, comercialização e a utilização de produtos destinados à alimentação de ruminantes que contenham em sua alimentação proteínas e gordura de origem animal. Brasília, 2004.

BRASIL, MINISTÉRIO DO MEIO AMBIENTE. Resolução CONAMA 375/2006. Define critérios e procedimentos para o uso agrícola de lodos de esgotos gerados em estações de tratamento de esgoto sanitário e seus produtos derivados, e dá outras providencias. Brasília, 2006.

COSTA, M.S.S.M.; COSTA, L.A.M.; PELÁ, C.J.S.; DECARLI, L.D.; MATTER, U.F. Desempenho de quatro sistemas para compostagem de carcaça de aves. Revista Brasileira de Engenharia Agrícola e Ambiental, Campina Grande - PB, V.10, n.3, p.692-698, 2006.

DAM,A.; NIBBELINK, B.G.; WARD, D. Windrow Composting of Poultry Carcasses. Order n. 09-017, AGDEX 720/450, April 2009. Disponível em: http://www.omafra.gov.on.ca/english/engineer/. Acesso em: 01/02/2011.

DEFILIPO, B.V.; RIBEIRO, A.C. Análise Química do Solo (Metodologia) - Boletim de Extensão. $2^{a}$ ed. Viçosa, 1997. 26p.

FLYNN, R.P.; WOOD, C.W. Temperature and Chemical Changes During Composting of Broiler Litter. Compost Science \& Utilization, v.4, n,3, p.62-70. 1996. 
GOLUEKE, C.G. Composting combined refuse and sewage sludge. Compost Science land utilization, USA, 1980.

GRAVES, R.E.; HATTEMER, G.M.; STETTLER, D.; KRIDER, J.N.; CHAPMAN, D. Composting. In: UNITED STATES DEPARTAMENT OF AGRICULTURE, NATURAL RESOURCES CONSERVATION SERVICE. Part 637 Environmental Engineering - National Engineering Handbook. Washington, 2000. 88p.

GUARDIA, A.; PETIOT, C.; ROGEAU D. Influence of aeration rate and biodegradability fractionation on composting kinetics. Waste Management, n. 28, p.73-84, 2008.

HARADA, Y.; YNOKO, A. Relationship between cation-exchange capacity and the degree of maturity of city refuse composts. Soil Sci. Plant Nutr. v.26, p.353-362, 1980.

KIEHL, E.J. Fertilizantes Orgânicos. São Paulo: Editora Agronômica Ceres. 1985, 492p.

KUMAR, V.R.S., SIVAKUMAR, K., PURUSHOTHAMAN, M.R., NATARAJAN, A.; AMANULLAH, M.M. Chemical Changes During Composting of Dead Birds With Caged Layer Manure. Journal of Applied Sciences Research, v.3, n.10, p.1100- 1104. INSInet Publication, 2007.

LUCAS JR., J.; AMORIM, A.C. Manejo de dejetos: fundamentos para a integração e agregação de valor. In: ZOOTEC, 2005, Campo Grande, MS. Anais... Campo Grande: ZOOTEC, 2005. p. 1-33.

MATOS, A.T.; VIDIGAL, S.M.; SEDIYAMA, M.A.N.; GARCIA, N.C.P.; RIBEIRO, M.F. Compostagem de alguns resíduos orgânicos utilizando-se águas residuárias da suinocultura como fonte de nitrogênio. Revista Brasileira de Engenharia Agrícola e Ambiental, v.2, n.2, p.199-203, 1998

MOREIRA, D.A.; MATOS, A.T.; SARTORI, M.A.; SILVA, N.C.L.; BARROS, R.T.P.; LUIZ, F.A.R. Perda de carga no fluxo de ar forçado em colunas de material orgânico com diferentes profundidades e estádios de degradação bioquímica. Engenharia na Agricultura, v.16, n.2, p.238-247. 2008.

ORRICO JÚNIOR, M.A.P.; ORRICO, A.C.A.; LUCAS JÚNIOR, J. Compostagem dos resíduos da produção agrícola: cama de frangos e carcaças de aves. Engenharia Agrícola, Jaboticabal, v.30, n.3, p.538-545, 2010.

PAIVA, E.C.R., MATOS, A.T., SARMENTO, A.P., PAULA, H.M., JUSTINO, E.A. Avaliação de sistema de tratamento de carcaças de frangos pelo método da composteira-windrow. Revista Eletrônica de Engenharia Civil., v.1, p.19-27, 2012.

PEREIRA NETO, J.T. On the treatment of Municipal refuse and sewage sludge using aerated static pile composting - A low cost technology approach. 1987. 272f. Tese (Doutorado em Engenharia Sanitária e Ambiental). Leeds Metropolitan University, Leeds, Inglaterra.

PEREIRA NETO, J.T.; NOBREGA, C.C.; STENTIFORD, E.I. A hybrid mode of aeration for aerated static pile composting systems. In Proceedings of the $7^{\text {th }}$ International Conference on Solid Waste Management and Secondary Materials. Philadelphia, PA, USA, December, 1991, section 4B.

RIBEIRO JUNIOR, J.I. .Análises estatísticas no SAEG. Viçosa: UFV. 2001. 301p.

RASAPOOR, M.; NASRABADI, T.; KAMALI, M.; HOVEIDI; $H$. The effects of aeration rate on generated compost quality, using aerated static pile method. Waste Management, n. 29, p. 570 573, 2009.

ROS, M.; GARCIA, C.; HERNANDEZ T.A full-scale study of treatment of pig slurry by composting: Kinetic changes in chemical and microbial properties. Waste Management, n.26, p.1108-1118, 2006.

SESAY, A.A.; LASARIDI, K.E.; STENTIFORD, E.I. Aerated static pile composting of municipal solid waste (MSW): a comparsion of positive 
pressure aeration with hybrid positive and negative aeration. Waste Management Research, v.16, n.3. p.264-272, June 1998.

SILVA, N.C.L., MATOS, A.T., SARTORI, M.A., MOREIRA, D.A., BARROS, R.T.P., LUIZ, F.A.R. Variação na pressão estática de ar insuflado em diferentes vazões especificas em colunas de material orgânico com diferentes estádios de degradação bioquímica. Acta Sci. Agron. v.30, n.2. p.165-170. 2008.

SILVA, R.A. Frango de Corte. Curitiba: Secretaria de Estado da Agricultura e do Abastecimento/ Departamento de Economia Rural. 2012. 4p. Disponível em: http://www.agricultura. pr.gov.br/modules/qas/uploads/3170/frango de corte 17agosto 2012.pdf. Acesso em: $05 / 09 / 2012$.

STENTIFORD, E.I.; PEREIRA, N.; MARA, D.D. Diversity of composting system. In: Low Cost Composting - Research Monographs in Tropical Public Health Engineering. University of Leeds, Edited by D. D. Mara. March, 1996. p.22-28.

WANG, K.; LI, W.; GUO, J.; ZOU, J.; LI, Y.; ZHANG. L. Spatial distribution of dynamics characteristic in the intermittent aeration static composting of sewage sludge. Bioresource Technology, n.102, p.5528-5532, 2011. 